\title{
Crimen organizado (narcotráfico) y conservación ambiental: el tema pendiente de la seguridad pública en México*
}

DOI: https://doi.org/10.18046/recs.i33.4076

Organized Crime (Drug Trafficking) and Environmental
Preservation, the Pending Issue of Public Safety in Mexico

José Luis Carpio-Domínguez ${ }^{* *}$

Universidad Autónoma de Tamaulipas (Reynosa, México)

\footnotetext{
* El estudio se deriva del proyecto doctoral "Redes sociales y actuación del Estado en la posesión de animales exóticos: estudio en grupos criminales, servidores públicos y personas civiles en Tamaulipas, México” financiado por el Consejo Nacional de Ciencia y Tecnología (CONACyT). Artículo de investigación recibido el 10.06.2020 y aceptado el 03.01.2021.

${ }^{* *}$ Doctorante en Ciencias Sociales con Orientación en Desarrollo Sustentable por el Instituto de Investigaciones Sociales de la Universidad Autónoma de Nuevo León (México), Maestro en Criminología y Ciencias Forenses por la Universidad Autónoma de Tamaulipas (México) y Licenciado en Criminología por la Universidad Noroeste de Chihuahua (México). Actualmente, profesor investigador en Criminología Verde adscrito a la Unidad Académica Multidisciplinaria Reynosa-Aztlán de la Universidad Autónoma de Tamaulipas (México). Correo electrónico: jcarpio@docentes.uat.edu.mx ORCID: https://orcid.org/0000-0001-8458-5189
} 


\section{Cómo citar/How to cite}

Carpio-Domínguez, José Luis (2021). Crimen organizado (narcotráfico) y conservación ambiental: el tema pendiente de la seguridad pública en México. Revista CS, 33, 237-274. https://doi.org/10.18046/recs.i33.4076 


\section{Resumen}

El presente estudio explora la incursión de grupos criminales dedicados al narcotráfico en las áreas naturales protegidas (ANP) de México, enfocándose en las implicaciones sociales, económicas y ambientales de la presencia de estos grupos dentro de estas áreas para los esfuerzos de conservación, lo cual permite incluir la dimensión ambiental del desarrollo sustentable en el paradigma de la seguridad pública. Metodológicamente, se realizaron entrevistas semiestructuradas a servidores públicos de las ANP a nivel nacional, abordando de manera diacrónica el período de guerra contra el narcotráfico, encontrando que las ANP siempre han figurado, en este escenario, como territorios de siembra y movilización de droga y como terrenos estratégicos de dominio, lo que ubica al medio ambiente y a las personas dentro y cerca de las ANP en situaciones de inseguridad.

\section{PALABRAS CLAVE:}

conservación ambiental, seguridad pública, narcotráfico, áreas naturales protegidas, criminología verde

This study explores the incursion of criminal groups dedicated to drug trafficking in Natural Protected Areas (NPAs) of Mexico. Focusing on the social, economic, and environmental impact of the incidence of these groups in the NPAs conservation efforts, our approach allows the inclusion of the environmental dimension of sustainable development in the paradigm of public security. Methodologically, semi-structured interviews were conducted with public servants of the NPAs at the national level, examining the war against drug trafficking period in a diachronic manner. The results of our research show that NPAs have always been part of the drug trafficking scene, as territories of cultivation and mobilization of drugs and as strategic control areas, placing the environment and people of the NPAs in situations of insecurity.

\section{KEYWORDS:}

Environmental Preservation, Public Security, Drug Trafficking, Natural Protected Areas, Green Criminology 



\section{Introducción}

En la última década, México se ha enfrentado al desafío de garantizar la seguridad pública a través del combate al narcotráfico a nivel nacional, situación que desde su origen estuvo relacionada con factores sociales, económicos, de relaciones internacionales, institucionales y también ambientales; quedando estos últimos en la periferia de los intereses públicos, políticos y académicos. Este artículo aborda el impacto del narcotráfico en los esfuerzos de conservación ambiental en el país, analiza la incursión de grupos criminales dedicados al narcotráfico en las áreas naturales protegidas (ANP) y la influencia de estos grupos en los esfuerzos de conservación. A su vez, abona conocimientos al paradigma de la seguridad pública desde la dimensión ambiental del desarrollo sustentable en los estudios enfocados en el crimen organizado, por lo que el presente estudio tiene como objetivo comprender los principales desafíos a los que se enfrentan los servidores públicos encargados de la protección, vigilancia y monitoreo de las ANP en México, derivados de la incursión de grupos criminales en algunas de estas áreas, así como de las repercusiones de las acciones de estos grupos en ellas, con la finalidad de visibilizar las nuevas y no tan nuevas formas de criminalidad y victimización ambiental en el marco de la seguridad pública en el país.

Como marco teórico, se encuadra la seguridad pública como un elemento imprescindible en los estudios relacionados con el medio ambiente y la naturaleza, desde la perspectiva de la criminología verde. Bajo este discurso, la seguridad pública es una cualidad de los espacios públicos y privados que se caracteriza por la inexistencia de amenazas que socaven o supriman los bienes y los derechos de las personas, y en la que existen razonables condiciones para el desarrollo de la propia existencia (García, 2002: 81); la construcción de esta cualidad implica la participación de múltiples recursos de la sociedad y del Estado (Centro de Estudios Sociales y de Opinión Pública (CESOP, 2006).

En este sentido, aunque la naturaleza escasamente figura dentro del paradigma tradicional de la seguridad pública (al menos en México), ofrece servicios universales y recursos naturales que son el capital natural del país (Comisión Nacional para el Conocimiento y Uso de la Biodiversidad [CONABIO], 2006), en donde se ubica y desarrolla el Estado mexicano, constituido por sus leyes, códigos, normas y, en consecuencia, es sujeto de derechos (Crespo, 2008). Por lo tanto, la naturaleza es un espacio público y, como menciona García (2002), en estos espacios no pueden existir amenazas que atenten contra la integridad del mismo, en tanto que, en caso de existir, representarían una amenaza a la seguridad de las personas, del Estado, la biodiversidad y los ecosistemas. La naturaleza debe considerarse dentro de los 
estudios de seguridad pública, sobre todo en aquellos donde convergen distintos fenómenos sociales, económicos y ambientales para comprender cómo se construyen las complejidades de estructuras, agentes, dinámicas e interrelaciones en la realidad social.

La presencia de grupos criminales mexicanos dedicados al narcotráfico dentro de las ANP no es un fenómeno nuevo en la práctica, pero sí en las investigaciones (Sainz, 2018), y se ha visibilizado a través de los reportes hemerográficos a lo largo del país (Aridjis, 2O2O; Ismael, 2019; Martínez, 2015; Melgoza, 2019; Méndez, 2015), situación que permite plantear este tema dentro de la perspectiva de la seguridad pública en México.

Para comprender la interrelación de la conservación ambiental en las ANP y el crimen organizado (narcotráfico) planteada en el presente estudio, se toma como referencia la guerra contra el narcotráfico en México, ya que evidenció la influencia y el poder de los grupos criminales en el territorio mexicano; sin embargo, es necesario aclarar que el término guerra contra el narcotráfico es una construcción discursiva que hace referencia al proceso de securitización del combate al narcotráfico que dio inicio en el sexenio del expresidente Felipe Calderón Hinojosa (2006-2012), ya que nunca existió alguna declaración de guerra propiamente contra el narcotráfico por parte del Estado mexicano. El término guerra contra el narcotráfico es utilizado en este estudio únicamente para delimitar y ubicar temporalmente el fenómeno de estudio (Figura 1).

FIGURA 1 Ubicación temporal del estudio de grupos criminales en las ANP de México en el contexto del combate al narcotráfico en el país

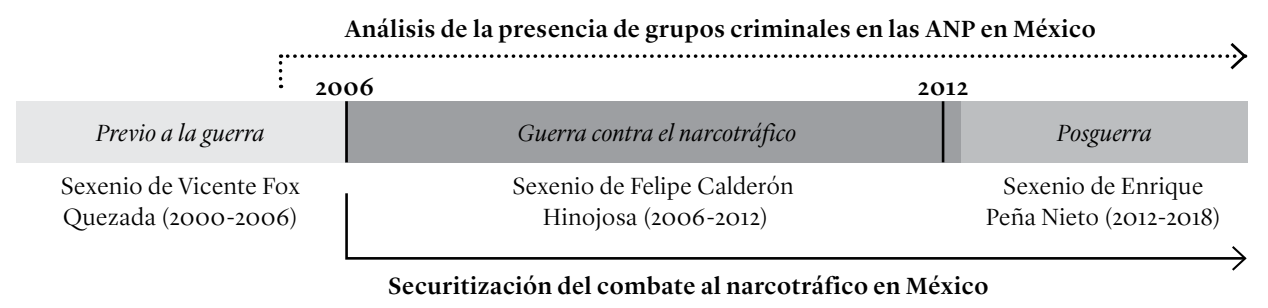




\section{El cultivo de droga, la guerra contra el narco y la posguerra en México}

Determinar en qué momento histórico los productores y traficantes de estupefacientes en México comenzaron a ocupar las ANP, implica reconocer que la producción de drogas en el campo, como actividad agrícola, existía mucho antes de considerarse ilegal en la década de 1920 (Astorga, 2005). Las políticas de prohibición de producción $\mathrm{y}$ tráfico de drogas (principalmente marihuana y amapola), en la primera mitad del siglo XX, condujeron a que la producción de droga, ahora ilegal, migrara hacia lugares fuera de la mirada pública y a la sombra de las fuerzas del Estado (Valdés, 2013).

Esta situación ha permanecido hasta la actualidad y, en los años previos al inicio de la guerra contra el narcotráfico en 2006, el fenómeno estuvo fuera del interés público (Valdés, 2013), puesto que las comunidades cercanas a los campos de producción de drogas como la marihuana y la amapola eran constantemente beneficiados de la derrama económica que representa este negocio de producción y tráfico ilegal. Además, de acuerdo con los registros, las alianzas con servidores públicos en esta actividad permitieron que se siguiera desarrollando sin problemas en una pax narcótica (Chabat, 2015; Hernández, 2014; Palacios; Serrano, 2010; Valdés, 2013). Sin embargo, en 2006, durante el sexenio presidencial de Felipe Calderón Hinojosa, al plantearse el narcotráfico como un problema de salud pública, este se convirtió en la principal amenaza a la seguridad nacional (Moloesnik; Suárez de Garay, 2012) y marcó un antes y un después en el tema de la seguridad pública y la historia del narcotráfico en México.

En este período, la seguridad pública pasó a ser el eje central de las actuaciones gubernamentales, mientras el discurso dominante enunciaba que las actividades relacionadas con el narcotráfico, entendido como una entidad no gubernamental, le disputaban al Estado el control del territorio, afectando severamente la integridad, estabilidad y permanencia del Estado mexicano (Ley de Seguridad Nacional, 2005, como se citó en Moloesnik; Suárez de Garay, 2012). Fue bajo este discurso que se encaminaron acciones para combatir al narcotráfico en México, resultando en enfrentamientos armados, división de grupos criminales, homicidios, entre otras consecuencias propias de las guerras, así como una justificable percepción de inseguridad en la población (Rosen; Zepeda, 2015).

Como parte de las acciones del Estado contra el narcotráfico, los operativos de destrucción de cultivos de marihuana y amapola, por parte de las fuerzas armadas de los gobiernos estatales y federales, y del ejército mexicano, se convirtieron en una estrategia fundamental para reducir la materia prima del mercado ilegal de droga, destacando que muchos de estos campos de cultivo se encontraban enclavados en lo 
profundo de las sierras de estados como Sinaloa, Chihuahua, Durango, Michoacán, Oaxaca y Tamaulipas (Gaussens, 2018). Además, muchos estados son terreno fértil para todo tipo de comercio ilegal (madera, tabaco, armas y droga) y para la operación de laboratorios clandestinos para el procesamiento de la droga, por lo que comúnmente se les conoce a estas zonas como triángulos dorados (Maldonado, 2011), ya que, por sus características geológicas, las conexiones por vía terrestre representan un desafío en la comunicación con otros lugares más urbanizados y, en consecuencia, para el ingreso de las fuerzas del Estado. Cabe señalar que estas extensas áreas a menudo coinciden, total o parcialmente, con los terrenos decretados como áreas naturales protegidas (Vázquez, 2018).

\section{Las áreas naturales protegidas en México}

Las áreas naturales protegidas (ANP) fueron creadas para la protección y conservación de la diversidad de animales, plantas y ecosistemas que ubican a México en el cuarto lugar a nivel mundial en biodiversidad, y como uno de los doce países más megadiversos del mundo (CONABIO, 2009). De acuerdo con el Convenio de Diversidad Biológica (Organización de las Naciones Unidas, 1992: 3), "un área protegida es un área definida geográficamente que haya sido designada o regulada y administrada a fin de alcanzar objetivos específicos de conservación", la cual, de manera institucionalizada, es una entidad de protección ambiental a través de la conservación a cargo del Estado.

En México, las ANP son aquellas en las que los ambientes originales no han sido significativamente alterados por la actividad del ser humano o que requieren ser preservadas y restauradas (Art. 44 de la Ley General de Equilibrio Ecológico y Protección al Ambiente). El procedimiento para que un territorio sea considerado ANP se encuentra a cargo de la Secretaría de Medio Ambiente y Recursos Naturales (SEMARNAT), quien integra al Sistema Nacional de Áreas Naturales Protegidas aquellos territorios que por su biodiversidad y características ecológicas son consideradas de especial relevancia en el país (según el Art. 74 de la misma ley).

Las ANP son espacios en los que se busca frenar el impacto de las actividades humanas y, por su importancia natural, se convierten en zonas estratégicas para la conservación de la biodiversidad que garantizan de alguna manera la vida, generan servicios ambientales como aportar aire puro, agua limpia, regular el clima, producir alimentos de consumo humano, la mitigación del cambio climático, beneficios paisajísticos y culturales, y, además, son el hábitat de especies de flora y fauna (Secretaría de Medio Ambiente, 2020). 
De acuerdo con la Comisión Nacional de Áreas Naturales Protegidas (CONANP, 2020), en México existen 187 ANP, divididas así: 67 parques nacionales, 47 reservas de la biosfera, 41 áreas de protección de flora y fauna, 18 santuarios, 8 áreas de protección de recursos naturales, 5 monumentos naturales y 1 área de protección de recursos naturales. Estas ANP se encuentran distribuidas por regiones (direcciones regionales), de acuerdo con sus características climáticas, geográficas y geológicas, y abarcan un total 18839521 hectáreas a nivel nacional (Cuadro 1).

CUADRO 1 Direcciones regionales de las áreas naturales protegidas en México

\begin{tabular}{|c|c|c|}
\hline Direcciones Regionales & Áreas Naturales & Hectáreas \\
\hline Centro y Eje Neovolcánico & 36 & 1729164 \\
\hline Noroeste y Alto Golfo de California & 9 & 2230372 \\
\hline Planicie costera y Golfo de México & 13 & 2310190 \\
\hline Norte y Sierra Madre Occidental & 11 & 2301009 \\
\hline Noreste y Sierra Madre Oriental & 17 & 3246339 \\
\hline Península de Baja California y Pacífico Norte & 19 & 43471482 \\
\hline Frontera sur, Istmo y Pacífico Sur & 28 & 11461244 \\
\hline Occidente y Pacífico Centro & 29 & 15526963 \\
\hline Península de Yucatán y Caribe Mexicano & 25 & 8562758 \\
\hline TOTAL & 187 & 90839521 \\
\hline
\end{tabular}

Fuente: elaboración propia con datos de la CONANP (2020).

De la superficie total de las ANP, 21886692 hectáreas son de conservación terrestre (Figura 2), lo que corresponde al 11,14 \% del territorio nacional (CONANP, 2019), mientras que el resto (69 458748 hectáreas) son de superficie marina.

Entre los principales problemas a los que se enfrenta la biodiversidad mexicana se encuentran la pérdida de suelo (derivada de la conversión de suelos naturales a sistemas productivos), la contaminación, el cambio climático, el tráfico ilegal de especies, la extracción insostenible de los recursos y la introducción de especies exóticas o invasoras (CONABIO, 2020). La investigación científica reciente aborda algunos de estos problemas ambientales desde la perspectiva de la seguridad pública 


\section{FIGURA 2 Áreas naturales protegidas de México}

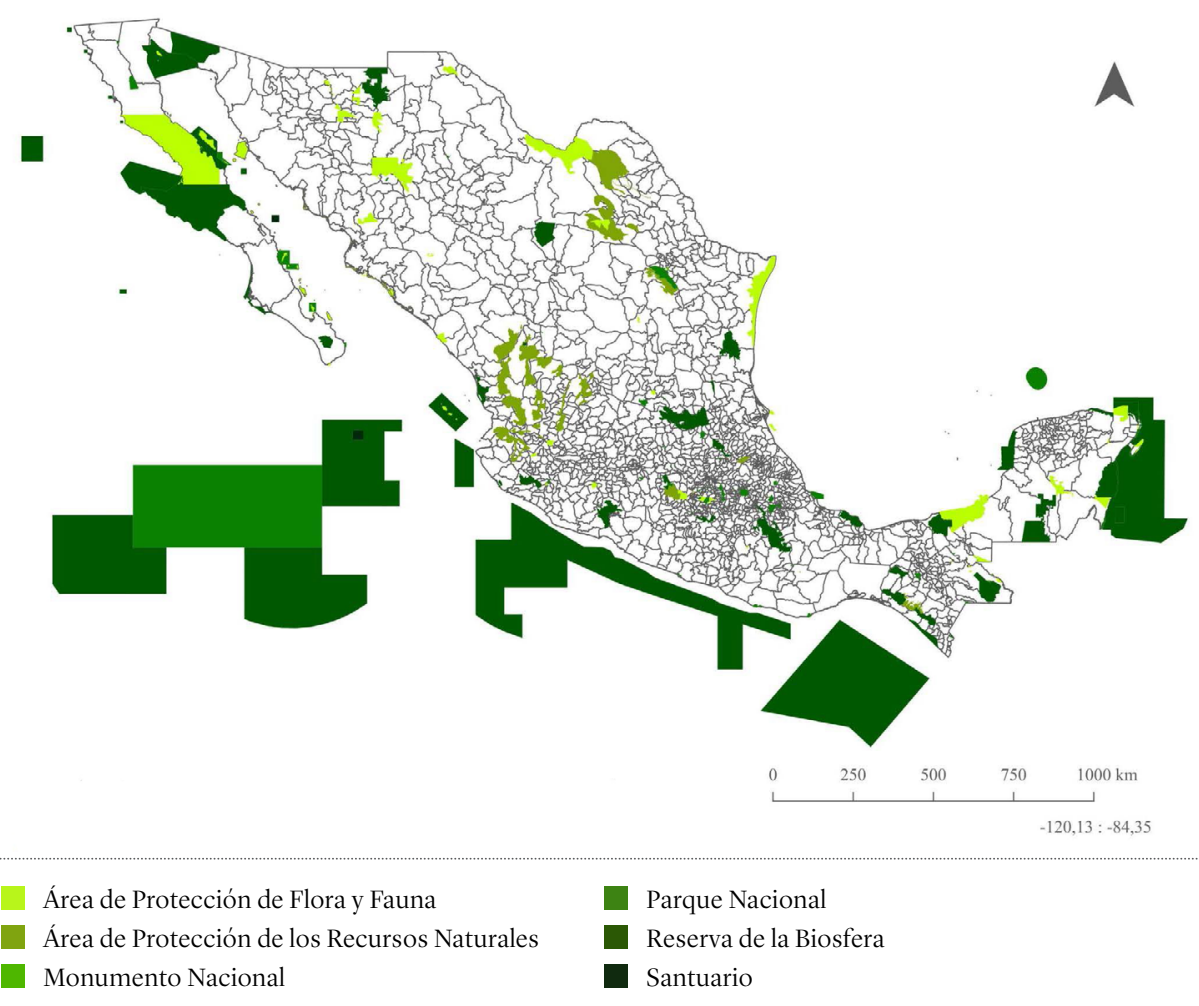

Fuente: elaboración propia con datos de la Secretaría de Medio Ambiente y Recursos Naturales (SEMARNAT, 2017).

y sus ciencias afines en México, destacando los trabajos de Sosa (2011); Alvarado (2012); Paz y Risdell (2014); Toledo (2015); Carpio, Vargas, Villarreal y Meraz (2018); Arroyo-Quiroz y Wyatt (2018), y Peralta (2018), los cuales han permitido comprender cómo las actividades humanas actuales, enfocadas en los crímenes y delitos ambientales, han afectado el medio ambiente. Sin embargo, es necesario ampliar y generar conocimientos sobre las afectaciones que los problemas sociales como el narcotráfico tienen en el medio ambiente.

\section{Narcotráfico y áreas naturales protegidas}

El presente tema de estudio fue planteado inicialmente, a través de reportes hemerográficos, en el año 2015, cuando los encabezados enunciaban las afectaciones de 
grupos criminales en las actividades de los servidores públicos dentro de las ANP con titulares como: "Delincuencia frena creación de áreas naturales protegidas y afecta crimen organizado monitoreo de ANP en entidades: CONANP" (Martínez, 2015; Méndez, 2015). A partir de entonces, los casos reportados por los medios de comunicación sobre el tema han ido en aumento, trayendo como consecuencia que las ANP sean llamadas narcorreservas (Melgoza, 2019). En la investigación sobre el tema, se encuentran los estudios de Vázquez (2018) y Sainz (2018), quienes establecen que las ANP están expuestas a problemas derivados del narcotráfico, como la siembra de drogas, la deforestación, las guerrillas entre grupos criminales y el creciente interés por los territorios y servicios ambientales que ofrecen.

Esta situación ha derivado no solo en afectaciones de carácter estrictamente ambiental, sino en secuestros, golpes, intimidación-amenazas, privaciones de libertad y un aumento considerable de casos reportados de homicidios de guardaparques, científicos, ambientalistas y miembros de comunidades cercanas a las ANP, y que son adjudicados al narcotráfico y a servidores públicos relacionados a los grupos criminales (Aridjis, 2O2O; Melgoza, 2019; Soberanes, 202O). Por tanto, la presencia de estos grupos en las ANP son una realidad en la cual los problemas de seguridad pública afectan también la dimensión ambiental del desarrollo sustentable.

En 2019, el Centro Mexicano de Derecho Ambiental (CEMDA) publicó el Informe sobre la situación de las personas defensoras de derechos humanos ambientales, en donde se describe el contexto en el cual se ejerce el derecho a defender los derechos humanos ambientales, con el objetivo de visibilizar los riesgos a los que se exponen estas personas en México. El informe menciona que, en el período 2012-2018, se identificaron 460 casos de ataques a personas defensoras de los derechos de la tierra, el territorio y el medio ambiente, siendo 2015 y 2016 los años con un mayor número de ataques. Además, el principal sector económico donde se realizan las agresiones a este grupo social es el de la energía eléctrica, seguido por el hidráulico, la minería y las vías de comunicación. En cuanto a la ubicación, son los estados de Oaxaca, Sonora, Estado de México, Puebla, Chihuahua, Guerrero, Veracruz y Chiapas los que tienen el mayor número de agresiones contra este grupo social (CEMDA, 2019).

De igual manera, el informe describe que, en el año 2019, se registraron 39 casos de agresiones, en donde el 4,8 \% fue atribuido al crimen organizado, y el 2,4 \%, a grupos armados (CEMDA, 2019), no especificando los estados de la república, si fueron dentro de las ANP o bien si las variables grupos armados y crimen organizado realizaban actividades de narcotráfico. Sin embargo, los registros hemerográficos establecen que las áreas naturales protegidas más peligrosas se encuentran en los estados de Baja California, Sinaloa, Sonora, Chihuahua, Nuevo León, Tamaulipas, Coahuila, Durango, Hidalgo, Tlaxcala, Veracruz, Jalisco, Estado de México, Chia- 
pas, Oaxaca y Guerrero (Ismael, 2019), mismos que representan el $50 \%$ del total de estados de México.

La distribución geográfica de los territorios de los grupos criminales dedicados al narcotráfico ha ido modificándose a través de los años a lo largo del país, consecuencia de la ruptura de los pactos entre los grupos dominantes y los acuerdos informales de reciprocidad entre las autoridades y estos grupos (Figura 3). Al respecto, los grupos criminales se asientan en un determinado territorio por dos razones: la búsqueda del control y la expansión de sus territorios de acción (Fuerte, 2016).

En la Figura 3 se muestra la distribución territorial de los 8 grandes grupos criminales dedicados al narcotráfico (cárteles de la droga); sin embargo, como se

\section{FIGURA 3 Distribución territorial de los principales grupos criminales en México hasta 2015}

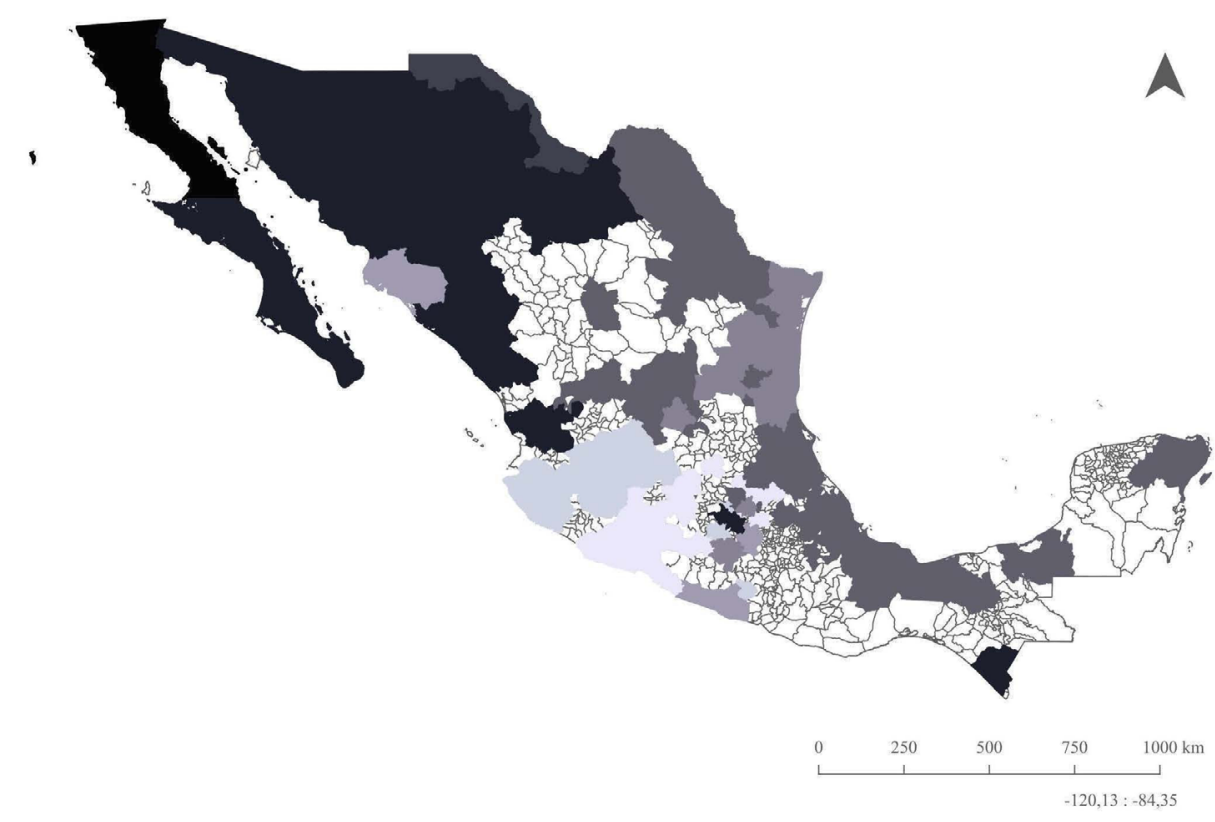

\section{Grupos del crimen organizado}

- Cartel de Tijuana

- Cartel del Sinaloa

- Cartel de Juárez
Cartel de los Zetas

Cartel del Golfo

Cartel de los Beltrán Leyva
Cartel de los Caballeros Templarios

Cartel de Jalisco Nueva Generación 
mencionó anteriormente, estos grupos se fragmentaron en células más pequeñas y especializadas (alrededor de 80 grupos) (Muedano, 2018) que han ido tomando fuerza y han destacado por la violencia que ejercen sobre los territorios y los enfrentamientos con otros grupos. Aunque no hay datos oficiales de cuánto territorio han perdido o ganado cada uno, se destacan entre los nuevos grupos criminales: Cartel de Jalisco Nueva Generación (CJNG), Los Zetas, La Familia Michoacana, Cártel del Noreste (CDN), Cartel de Santa Rosa de Lima, entre otros, que han ido ocupando territorios nuevos y adaptándose a las nuevas formas de criminalidad para mantener sus estructuras delictivas y sus territorios de dominio.

Estas grandes extensiones territoriales dominadas por grupos criminales dedicados al narcotráfico comprenden entornos tanto rurales como urbanos, así como amplias extensiones de territorio alejados de los centros de población, en donde es común que coincidan con las ANP. Este fenómeno fue documentado anteriormente en otros países de Latinoamérica como Perú (Núñez, 1999), Nicaragua (Malamud; García, 2011), Panamá (El narcotráfico, 2018) y Colombia (Cepeda, 2011; Morales, 2017), en los cuales, en algún momento, los grupos criminales han dominado grandes extensiones territoriales dedicadas a la protección de la naturaleza. Sin embargo, en Colombia los conflictos armados fueron determinantes en las formas de entender, ocupar y usar el territorio (Morales, 2017), ya que las disputas entre los grupos armados y el Estado tuvieron como consecuencia la ocupación de espacios de gran riqueza natural como la Amazonia, el Chocó, la Cordillera de los Andes y la Orinoquía:

El Programa de Naciones Unidas para el Desarrollo (PNUD) ha identificado que, de los 125 municipios que necesitan atención especial en el posconflicto, el $90 \%$ tiene algún tipo de restricción ambiental en el uso de suelos. Como ejemplo: 41 de los 47 municipios con "prioridad alta" para la atención por la incidencia del conflicto tienen parques naturales o reservas forestales y en ocho de los municipios con "prioridad" la totalidad del suelo tiene algún tipo de protección. (Morales, 2017: 5)

De igual manera, Morales (2017) establece que este fenómeno trajo como consecuencia dos aspectos opuestos: graves daños ambientales causados por las actividades ilícitas de estos grupos en las zonas y, por otra parte, propició la conservación de los territorios quedando al margen de los grandes proyectos de desarrollo.

En México, las amenazas a los esfuerzos de conservación no solo provienen del narcotráfico, sino también del mismo aparato institucional del gobierno, otras formas de crimen organizado, empresas privadas y paramilitares (CEMDA, 2019). Sin embargo, son de interés para el presente estudio las que son representadas por el narcotráfico, dada su capacidad de adaptación a los cambios sociopolíticos, de organización y violencia (Buscaglia, 2012; Olinger, 2013; Williams, 2010). En este 
sentido, los registros científicos y hemerográficos permiten referenciar geográficamente los territorios de los distintos grupos criminales del país y, junto con los datos proporcionados por la SEMARNAT, identifican los territorios de los 8 grupos criminales más grandes dedicados al narcotráfico (hasta 2015) dentro de las ANP, por lo que la distribución territorial de estos grupos coincide con 75 ANP de todas las direcciones regionales (Figura 4).

Como se muestra en la Figura 3, los territorios de distribución de estos grupos criminales coinciden, en su mayoría, con territorios designados como ANP (en color verde), representando el 40,11 \% del total de áreas naturales protegidas a nivel nacional. \begin{tabular}{l|l} 
FIGURA 4 & $\begin{array}{l}\text { Confluencia de territorios del narcotráfico en Áreas Naturales Protegidas } \\
\text { en México }\end{array}$
\end{tabular}

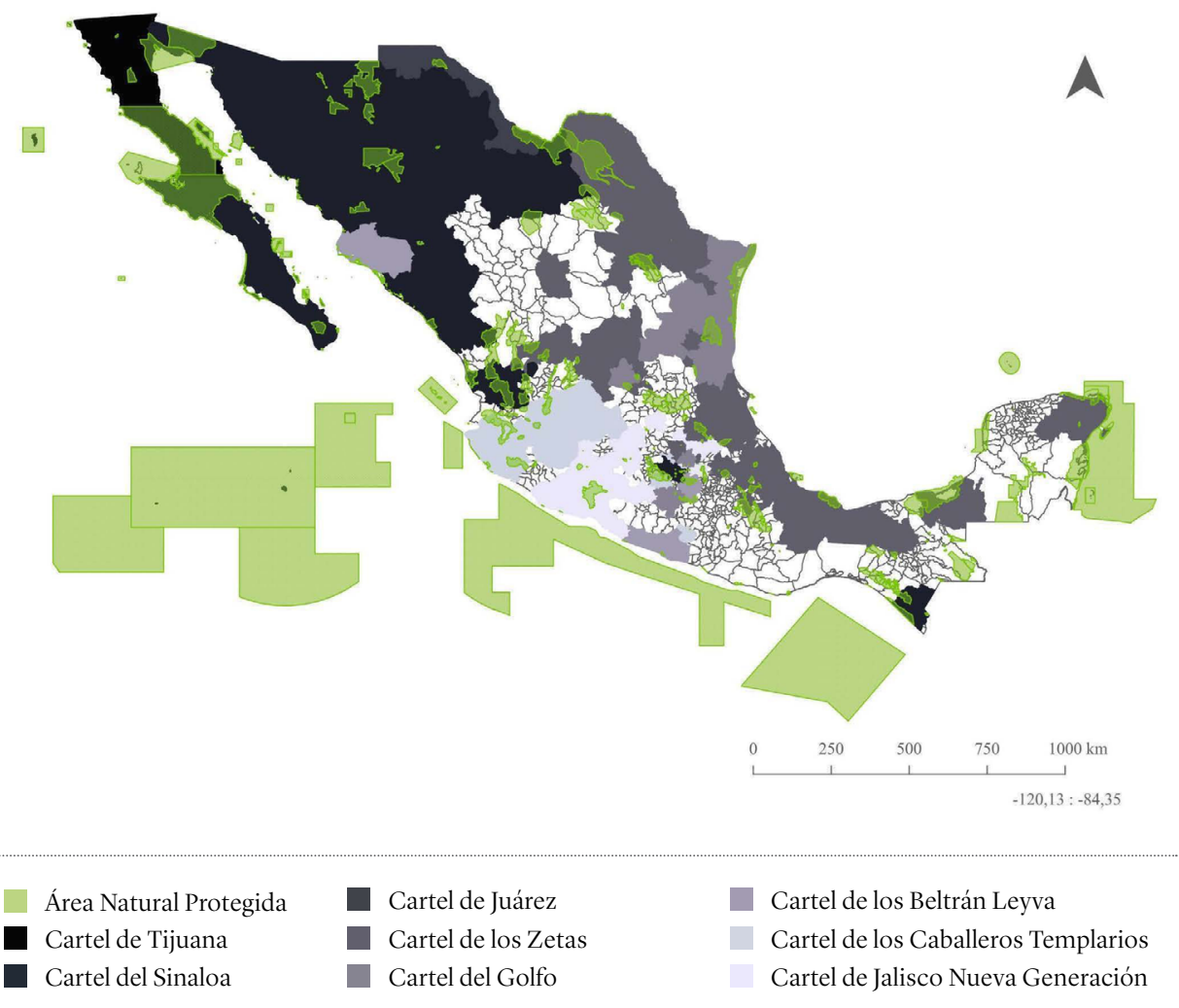




\section{Metodología}

\section{Tipo de estudio}

El presente estudio descriptivo y analítico se propone explicar la relación entre dos fenómenos que emergen en un contexto espaciotemporal determinado (Rojas-Soriano, 2015), explorando, a través del método cualitativo, las implicaciones de la presencia de grupos criminales dedicados al narcotráfico dentro de las Áreas Naturales Protegidas en México. Especialmente, se centra en analizar cuáles han sido las repercusiones de estos grupos en los esfuerzos de conservación (monitoreo, educación, aprovechamiento, ecoturismo, vigilancia, investigación científica, etc.) en México antes, durante y después de la guerra contra el narcotráfico (2006-2012).

\section{Características de la muestra}

Para cumplir con el objetivo planteado, se llevó a cabo un muestreo cualitativo no probabilístico, utilizando la técnica en cadena o bola de nieve. Esta técnica consiste en ubicar informantes que cumplan con los criterios de selección y pedirles que refieran a otros posibles participantes (Bernard, 2006). La muestra estuvo compuesta por 15 servidores públicos de la Comisión Nacional de Áreas Naturales Protegidas (CONANP) en 15 áreas naturales protegidas a nivel nacional.

En cuanto a la descripción de la población de estudio, por cuestiones de seguridad de las personas entrevistadas, se mantiene la confidencialidad de las identidades, puestos laborales, nombre de las ANP o sedes regionales, ya que algunos de los informantes contactados no accedieron a la entrevista, bajo el discurso de temer por su seguridad si ofrecían información sobre los grupos criminales dentro de las ANP o en las regiones cercanas.

\section{Instrumento de recolección y análisis de datos}

Se realizaron entrevistas semiestructuradas para la recolección de los datos, las cuales se llevaron a cabo de manera presencial, en algunos casos, y otras se realizaron de manera remota, a través de llamadas telefónicas por cuestiones de seguridad de ambas partes (entrevistador y entrevistado), todas durante el período comprendido entre septiembre de 2019 y junio de 2020. La duración de las entrevistas, en los casos presenciales, fue de una hora, mientras que el tiempo de entrevista en las llamadas telefónicas oscilaba entre una hora, y una hora y media. Las entrevistas se diseñaron para obtener una perspectiva diacrónica del fenómeno de estudio (antes, durante 
y después de la guerra contra el narcotráfico), así como para la obtención de subcategorías que permitieran profundizar en los desafíos de la conservación en México.

El diseño de la entrevista incorporó cuatro categorías previas: 1) la conservación ambiental antes de la guerra contra el narcotráfico; 2) estrategias de conservación durante la guerra; 3) estrategias de conservación en la posguerra, y 4) narcotráfico y amenazas actuales para la conservación.

En la primera categoría, se analiza el escenario de las ANP previo a la guerra, las actividades que se realizaban para procurar la conservación ambiental y las condiciones bajo las cuales desempeñaban dichas actividades, así como de las estrategias para la implementación de actividades de conservación y de desarrollo regional sustentable en las comunidades cercanas o dentro de las ANP.

En la siguiente categoría se analiza el contexto de la conservación ambiental en las ANP durante el período de guerra contra el narcotráfico (2006-2012), analizando el papel que desempeñaron las fuerzas del Estado dentro de las áreas, la influencia del conflicto armado en la participación ciudadana y el turismo en la zona, así como las principales estrategias utilizadas para procurar y garantizar el binomio seguridad-conservación. Esta categoría tiene como objetivo visibilizar el escenario de la guerra dentro de las ANP.

La categoría tres analiza las modificaciones en los patrones de actividad de los grupos criminales dentro de las ANP después de la guerra, la influencia del fenómeno en los ecosistemas locales y las consecuencias ambientales de este período de conflicto entre los grupos criminales y el Estado desde la percepción de los servidores públicos de las ANP. Esta categoría tiene el objetivo de comprender los efectos ocasionados por la guerra en estas instituciones, así como las estrategias utilizadas para retomar las acciones de conservación.

La cuarta y última categoría tiene como objetivo conocer las principales amenazas actuales a las actividades de conservación en las ANP, dentro del contexto de la seguridad pública, derivado de la permanencia de los grupos criminales dedicados al narcotráfico dentro las ANP de estudio.

\section{Resultados y discusión}

La Comisión Nacional de Áreas Naturales Protegidas (CONANP), desde su origen, en el año 2000, ha tenido como objetivos la administración de las áreas naturales protegidas y el impulso y aplicación de programas de desarrollo regional sustentable, los cuales se cumplen a través de los apoyos administrativos, financieros, de infraestructura y operación dentro y cerca de las ANP, así como de la elaboración 
de programas de manejo, administración y vigilancia de estas áreas, entre otras actividades relacionadas y dedicadas a la conservación ambiental. Estas actividades se desempeñaron de manera oportuna desde su creación; sin embargo, los bajos índices de seguridad pública en los años siguientes fueron determinantes para las condiciones bajo las cuales se llevaron a cabo y se realizan actualmente.

\section{El escenario previo a la guerra}

Para comprender el escenario de la conservación ambiental en las ANP, previo a la guerra contra el narcotráfico en México, es necesario mencionar que los decretos oficiales de la creación de las ANP se remontan a los primeros años del siglo XX, en 1917 (González; Cortés; Iñiguez; Ortega, 2014; Simonian, 1999; Vargas, 1997). Sin embargo, durante estos primeros años, las ANP se encontraron sin ninguna interacción institucional para su administración, es decir, "existieron únicamente en el papel" (CNDH, 2019: 22). Fue en el año 2000 cuando la CONANP tomó parte en estas acciones de conservación; a su vez, como se planteó anteriormente, los registros históricos establecen que la producción de narcóticos en México ha estado presente desde 1828, con la producción de marihuana en el estado de Sonora y de la adormidera blanca o amapola en Sinaloa desde 1886 (Valdés, 2013). Por esta razón, los decretos de las nuevas ANP fueron a la par del desarrollo de las actividades de siembra, cosecha, tráfico y venta de narcóticos en el país.

A pesar de la prohibición, en 1920, de cultivar y comercializar la marihuana en el país, y la de la amapola o adormidera seis años después, en 1926 (Valdés, 2013), las 6 décadas consecuentes (1920-1980) se desarrollaron en una paz aparente, entre la conservación ambiental pasiva y el narcotráfico agresivo que dominaba cada vez más territorios para sus actividades, a la sombra de las acciones institucionales de seguridad pública y del desinterés por el Estado de derecho. Esta situación se convirtió en una pax narcótica de beneficios para los productores de droga y servidores públicos de las dependencias de seguridad en el país.

A la par de las declaraciones de las nuevas ANP en este período, los grupos dedicados al narcotráfico fueron fortaleciéndose como verdaderas organizaciones criminales con características propias de una empresa (jerarquías, contrataciones, ascensos, etc.) y con una responsabilidad social empresarial que permitía algún tipo de desarrollo de las comunidades donde se encontraban estos grupos (Nájar, 2010; Solera, 2019; Sumano, 202O; Villatoro, 2012). Como tal, la producción de la marihuana ilegal se llevó a cabo en este período en 18 de los 32 estados de la república, en donde era común encontrar plantaciones de droga en estados como el Distrito Federal, Puebla, Estado de México, San Luis Potosí, Oaxaca, Guerrero, Querétaro, 
Guanajuato, Morelos, Hidalgo, Tlaxcala, Sonora, Colima, Veracruz, Nuevo León, Coahuila, Tamaulipas y Chihuahua. Mientras que la producción (siembra, cosecha y tráfico) de la amapola se desarrollaba ampliamente en el triángulo dorado correspondiente a los estados de Sinaloa, Chihuahua y Durango (Astorga, 2005, como se citó en Valdés, 2013). En ambos casos, las alianzas permitieron el enriquecimiento de las dos partes: los productores y traficantes de estas drogas, y los servidores públicos encargados de prevenir, regular y sancionar la ilegalidad del tráfico.

La creación de las áreas naturales protegidas se realizó de manera paulatina a través de este tiempo, por lo que los decretos de las nuevas ANP a menudo coincidían (y siguen coincidiendo) con territorios ya ocupados por grupos dedicados al narcotráfico, en donde era común que los servidores públicos encargados de la conservación se encontraran con sistemas institucionalizados de dominio ilegal en estas zonas, mismas que ya tenían una larga historia de conflictos entre grupos criminales vecinos por la lucha de los territorios.

En el presente estudio se evidenció que, aunque la extensión de los territorios de las ANP se encuentra bien delimitada, existen zonas dentro de ellas a las que los mismos trabajadores no pueden ingresar debido al alto riesgo que representa realizar acciones de conservación en lugares ubicados a horas o días de camino del poblado más próximo; por lo que, en algunos casos, no se realizan actividades de conservación en toda la extensión territorial de las ANP por el peligro de adentrarse hasta los territorios de los grupos criminales dentro de estas.

Como afirman algunos de los entrevistados: "desde la creación del ANP no hemos podido entrar a zonas que son parte del área natural, porque los conflictos entre los grupos no han dado tregua para poder realizar actividades de monitoreo biológico, vigilancia o proyectos de conservación" (comunicación personal, 08.05.2020) y "antes de la guerra contra el narco, era todo igual que ahora, no más que sin la presencia de soldados" (comunicación personal, 19.03.2020).

Sin embargo, las acciones de conservación en los años previos a la guerra contra el narcotráfico se desarrollaron sin mayor problema, en un estado de respeto, donde los encargados de las ANP no se inmiscuían en las actividades de los grupos criminales y viceversa, siempre que se guardara la discreción de la información sobre la ubicación de los terrenos de producción de droga y sus asentamientos, o bien de las rutas de tráfico. "La verdad es que estas personas [narcotraficantes] siempre han estado en la zona, pero antes eran muy respetuosos del trabajo que hacíamos, ahora ya no podemos ni voltear a verlos" (comunicación personal, 20.09.2019). 
Antes podíamos trabajar sin problema, siempre que no nos metiéramos con sus cosas, nosotros hacíamos todo lo que podíamos para la conservación y para trabajar con las comunidades; en esos tiempos, todos sabíamos quién andaba metido en esas cosas [narcotráfico] y generalmente todos en las comunidades ya sabían quiénes éramos y qué hacíamos allí, por lo que no nos molestaban. (Comunicación personal, 2.04.2O2O)

Esta situación permitió que el personal de la CONANP implementara proyectos de desarrollo regionales y de conservación ambiental con apoyo de las comunidades dentro y cerca de las ANP, de manera que se logró una aplicación de las estrategias de conservación y se permitió consolidar el andamiaje institucional de las ANP en el país.

Sin embargo, la paz no duró mucho tiempo en algunas ANP, ya que en 2006, 6 años después de la creación de la CONANP, con el decreto del narcotráfico como un problema de salud pública y bajo el discurso de que estos grupos atentaban contra la seguridad nacional (Buscaglia, 2012; Moloesnik; Suárez de Garay, 2012), se dio inicio a un fenómeno social de gran impacto en la historia del país y de las formas de llevar a cabo las acciones de conservación ambiental.

\section{La guerra contra el narcotráfico (2006-2012) y la conservación ambiental en las ANP}

La guerra contra el narcotráfico, en México, ya venía gestándose desde las décadas de 1970 y 1980 , debido al incremento de casos de adicción a narcóticos en Estados Unidos y las constantes presiones políticas entre los dos países. Estas razones fueron determinantes para ir perfilando las estrategias de actuación contra el narcotráfico con el fin de erradicarlo; sin embargo, para este período, el narcotráfico ya se encontraba estructurado como una empresa, fortalecida y combatiente ${ }^{1}$. Por otra parte, en este período, los avances en materia ambiental permitieron la consolidación de estructuras institucionales, una legislación sólida y la inclusión de la población en la conservación, procurando el desarrollo de las comunidades. Entre estos avances, se destaca la creación de la Secretaría de Desarrollo Urbano y Ecología (SEDUE), así como del Sistema Nacional de Áreas Naturales Protegidas (SINANP), la promulgación de la Ley General de Equilibrio Ecológico y Protección al Ambiente y la protección ambiental de casi el 1,5 \% de la superficie del país (Challenger, 1998, como se citó en Castañeda, 2006).

La iniciativa del Gobierno federal del año 2006 con relación a la securitización del combate al narcotráfico dio inicio a lo que se conocería como guerra contra el narcotráfico. El despliegue de las fuerzas del Estado tuvo como consecuencia una oleada 
de enfrentamientos entre estas y los grupos criminales. Esto ocasionó los niveles más altos de inseguridad en la historia moderna del país; situación que repercutió en todas las esferas sociales y de la que no escaparon las acciones de conservación ambiental, que, como se ha visto en el presente estudio, nunca estuvieron alejadas del escenario ilegal de los narcóticos, a raíz de sus cercanías territoriales.

Esta situación de vulnerabilidad ocasionó que el personal de las ANP del país se encontrara muchas veces en situaciones de conflicto y violencia, a causa de los enfrentamientos armados, ya que las fuerzas del Estado desarrollaban actividades de destrucción de plantaciones de droga en las zonas cercanas o dentro de las ANP, así como en las zonas marinas destinadas a la protección ambiental por donde transportaban la droga en botes o lanchas. Como se afirma en algunos de los testimonios, "los conflictos durante este período eran comunes en las cercanías y dentro del ANP, era común ver policías [federales, estatales] y personal de la SEDENA [Secretaría de la Defensa Nacional]" (comunicación personal, 8 de mayo de 2020); "a veces nos corrían de los lugares donde andábamos haciendo monitoreos de fauna marina, llegaban personas armadas en lanchas y nos corrían, y allí teníamos que parar el trabajo y volver otro día o la otra semana" (comunicación personal, 28.11.2019), y "en el caso de nosotros en el ANP, solo tenemos un grupo criminal (...) no hay paz pero estamos en calma" (comunicación personal, 19.03.2020).

Estos eventos de violencia dentro y cerca de las ANP (sobre todo en las comunidades) fueron constantes durante los años siguientes al inicio de la guerra, caracterizados por enfrentamientos armados, intimidaciones, privaciones de la libertad, golpes y homicidios. De acuerdo con los relatos de las personas entrevistadas, esta situación de vulnerabilidad derivó en casos graves de atentados contra el personal de las ANP.

A principios de 2010, dos compañeras fueron levantadas [privadas de la libertad], las trajeron por unas horas, pero hablamos con personas que tienen influencia con estos grupos, personas de allí de la comunidad donde trabajamos y las liberaron, las dejaron en un paraje y luego fuimos por ellas, no las golpearon, solo el susto. (Comunicación personal, 02.04.2020)

Un compañero que se encontraba haciendo monitoreo de fauna lo detuvieron camino al ANP, le quitaron cosas materiales, unas cámaras para monitoreo, unos ganchos herpetológicos y otras cosas, pero solo fue eso, todos sabemos que en otras circunstancias hubiera sido peor. (Comunicación personal, 19.03.2020)

Como menciona Valdés (2013), la naturaleza ilegal de los mercados (en este caso del narcotráfico) incentiva el uso de la violencia por dos motivos: 1) la conveniencia de ser quien fije las reglas de toda la actividad económica, y 2) la necesidad de ase- 
gurar, mediante la fuerza y el miedo, el cumplimiento de los acuerdos como método de resolución de conflictos y garantizar su control sobre territorios específicos. Por estas razones, la violencia no solo se limitó a las luchas entre los narcotraficantes y el Estado, sino que se representó en eventos violentos contra la población civil y hacia los servidores públicos de las ANP del país.

Recuerdo una vez, allá por el 2008, subimos [a la montaña] para hacer monitoreo de fauna junto con un grupo de estudiantes de la universidad y entre los árboles vimos unas camionetas, eran como 5 , tapadas con lonas y adentro se alcanzaban a ver armas de fuego, pronto tuvimos que alejarnos de allí, la verdad me dio miedo por la responsabilidad de la protección de los alumnos, no quiero ni pensar qué nos hubiera pasado si nos hubieran encontrado allí estas personas [narcotraficantes]. (Comunicación personal, 20.09.2019)

Por lo tanto, muchas de las actividades de conservación durante este período fueron severamente afectadas, pues, además de los enfrentamientos armados, se documentó la creación de narcolaboratorios dedicados al procesamiento de los derivados de la droga dentro de las ANP, principalmente en grupos criminales como el Cartel de Sinaloa y el Cartel de la Familia Michoacana (Impacta narcotráfico, 2013); estas situaciones derivaron en la cancelación de actividades de conservación en las ANP.

Para el año 2010, se cancelaron todas las actividades de conservación, los proyectos con las comunidades, vigilancia y el monitoreo biológico, fue hasta 2011 que se retomaron las brigadas de vigilancia, en 2012 comenzamos nuevamente las actividades en las comunidades y hasta 2013 que retomamos todas las actividades. (Comunicación personal, 08.05.2020)

Durante el período de guerra, los trabajadores de las ANP tuvieron que aprender a hacer actividades de conservación en zonas de inseguridad, ya que en ningún momento de su formación profesional o laboral se les capacitó para enfrentar un escenario de este tipo, y aunque las experiencias relatadas durante las entrevistas son muchas, se evidencia el gran impacto en las formas de conservar el medio ambiente en las ANP del país. "Cuando hay enfrentamientos no hacemos nada, pero cuando podemos entrar al ANP nuestras entradas son multipropósito, tratamos de hacer todo en una sola ida, ya sabes, monitoreamos cámaras, nos reunimos con la comunidad, etc., y ya después volvemos" (comunicación personal, 19.03.2020). "A nosotros nunca nos enseñaron en la carrera cómo actuar frente a situaciones así, todo lo hemos aprendido por experiencia y las experiencias de otros compañeros" (comunicación personal, 28.11.2019). 
Se suele considerar que la guerra terminó con el sexenio calderonista; sin embargo, la comprensión de la guerra contra el narcotráfico no puede ser definitiva porque se trata de un proceso que aún no ha acabado (Pereyra, 2012: 456), por lo que sus estragos en todos los niveles siguen presentes, a pesar de las nuevas estrategias de seguridad de los sexenios consecutivos. Permanece la hegemonía de estos grupos sobre las regiones y sus comunidades, pero también en las acciones de conservación ambiental en las ANP que coinciden en territorios de los grupos criminales. Al respecto, se rescatan tres aspectos importantes que fueron consecuencia de este período: 1) la capacidad de estos grupos para responder, resistir y adaptarse a los cambios políticos, de seguridad y sociales; 2) la fragmentación de los grupos en células criminales más pequeñas, y 3) la capacidad de los trabajadores de las ANP en el desarrollo de estrategias para llevar a cabo acciones de conservación ambiental en entornos de inseguridad.

\section{La posguerra, ¿qué cambió en la conservación ambiental? (después de 2012)}

Las condiciones de desarrollo de las actividades de conservación en el período de la posguerra siguieron vinculadas a la evolución de los índices de seguridad a nivel nacional y regional. Recién terminado el sexenio del presidente Felipe Calderón Hinojosa, la situación de inseguridad en las ANP fue dando tregua, ya que las acciones de conservación dentro de las ANP fueron reanudándose paulatinamente. Sin embargo, algunas cosas no cambiaron para el personal de la CONANP, como la presencia de los grupos criminales en las ANP, al igual que durante de la guerra, sobre todo en las áreas rurales (lejos de las grandes ciudades), en donde la vulnerabilidad sigue presente y el alcance de las acciones del Estado ya no llega. "Esta es la realidad de las ANP rurales, improvisar el trabajo, garantizar tu seguridad y la de tus compañeros y hacer lo mejor que se pueda para procurar la conservación ambiental" (comunicación personal, 02.04.2020).

No podemos pedir apoyo de estas instituciones [policía federal, SEDENA o Marina] porque el personal un día está y al otro no, a ellos los van rotando de los lugares, a nosotros no, entonces si lo hiciéramos nos relacionarían con ellos y pues ahorita no estaríamos aquí platicando. Además de que no podemos hacer denuncias de la presencia de estos grupos en el ANP, porque siempre hay gente involucrada con ellos [otros servidores públicos], por eso no tomamos el riesgo de decir algo, mejor hacemos lo que venimos a hacer en la medida de lo posible, ellos hacen los suyo y nosotros lo nuestro. (Comunicación personal, 08.05.2020) 
Esta situación de vulnerabilidad ha sido enfrentada por parte del personal de las ANP con estrategias aprendidas durante el período anterior, para lograr la conservación ambiental, en donde la población de las comunidades proporciona información sobre las condiciones de seguridad en las ANP para poder ingresar y realizar las actividades bajo ciertas limitaciones.

Lo que ha pasado es que ya sabemos por donde ir y por donde no dentro del ANP, y también preguntamos en las comunidades qué tan caliente [peligrosa] está la zona para ir a trabajar y pues si está muy reciente el conflicto o algo, nos devolvemos y preguntamos unos días después. (Comunicación personal, 02.02.2020)

Esta situación ha derivado en que solo puedan realizar acciones de conservación en algunos lugares y con restricciones de horario, ya que no pueden ingresar en la noche o sin avisar (a los grupos criminales) de las acciones que realizarán dentro del área natural protegida. Como afirma uno de los entrevistados: "prácticamente tenemos que pedir permiso para entrar y hacer nuestro trabajo y si algo nos llega a pasar, pues ni quién se entere" (comunicación personal, 08.05.2020).

Además, la vigilancia en estas zonas es constante por parte de los grupos criminales y, como parte de sus estrategias de seguridad, implementan retenes ilegales, lo que se ha convertido en una normalidad en las regiones; por tanto, la movilización dentro de la zona se encuentra regulada por estos grupos y ante cualquier irregularidad reaccionan con desconfianza.

Pero sí nos ha pasado que nos detienen en los retenes que ponen para preguntarnos qué andamos haciendo y qué vamos a hacer, incluso nos han encañonado, pero les explicamos lo que vamos a hacer y nos dejan, la verdad sí nos da miedo, es muy riesgoso.

(Comunicación personal, 19.03.2020)

Una de las afectaciones que más ha impactado en la conservación ambiental en las ANP del país es la pérdida de capital humano y social para la conservación y el desarrollo sustentable de las regiones, situación derivada de los conflictos entre grupos criminales y que ha sido abordada en trabajos de investigación (Maldonado, 2011; Ortiz, 2019) y reportes hemerográficos (Hernández, 2009; Nájar, 2017). Estos trabajos describen la interrelación que existe entre las comunidades rurales y la producción de narcóticos, ya que, de acuerdo a estos registros, estas comunidades representan la principal fuente de mano de obra para los procesos de siembra, mantenimiento y cosecha de drogas como la marihuana y la amapola, y también sobre la relación antagónica con las organizaciones criminales a través del surgimiento de grupos de autodefensas en estas comunidades, como es el caso de Michoacán (Rivera, 2014). 
[Las personas] de la comunidad son chutameros [productores de amapola] porque es lo que han hecho siempre, platicando con uno de ellos me dice: qué más puedo hacer, he sido chutamero desde que tenía 7 años, es lo único que sé hacer (...) aquí siembran lo que les deja dinero, si el frijol o el maíz les diera lo mismo en ganancias, pues sembrarían frijol o maíz. (Comunicación personal, 21.02.2O2O)

Sin embargo, en el presente estudio se identificó que las comunidades también desempeñan actividades de conservación ambiental guiadas por el personal de las ANP, en donde se elaboran proyectos de aprovechamiento sustentable de los recursos y se asesora para su creación, además, se promueve la creación de fuentes de empleo sostenibles a través del turismo ecológico, fabricación de artesanías, y se capacita sobre la importancia de la conservación de especies de flora y fauna de la zona.

Esta colaboración entre el personal de las ANP y las comunidades que habitan dentro y cerca de ellas se vio afectada durante el período de guerra y la posguerra, ya que, durante los conflictos armados, muchos pueblos y comunidades fueron diezmados, quedando abandonados parcial o completamente a lo largo del país.

Las comunidades que participan en los proyectos que implementamos dentro del ANP han sido severamente afectadas, incluso hay comunidades o pueblos fantasma, donde todos los habitantes han sido desplazados o asesinados. A veces terminamos los proyectos con una comunidad y a los meses o al año que volvemos ya no hay nadie. Esto pasa por el conflicto entre los grupos criminales, porque si un grupo estuvo cerca de una comunidad, cuando este pierde el territorio ante otro grupo, los nuevos toman venganza contra las personas. Además, cuando un grupo de estos está cerca de una comunidad, es común que se lleven una vaca para comer o, en el peor de los casos, golpes y violaciones de mujeres en las comunidades, porque estas personas [narcotraficantes] bajan a la comunidad. (Comunicación personal, 08.05.2020)

La migración forzada a causa del narcotráfico fue bien documentada en varias investigaciones (Barrios, 202O; Cruz, 2017; Durin, 2012; Rubio, 2014; Velázquez, 2017); sin embargo, los desplazamientos y agresiones contra las comunidades cercanas a las ANP no ocuparon un lugar justo en estos trabajos, situación que pudo deberse a la inaccesibilidad de los datos o, bien, porque estas comunidades se encuentran en la periferia del interés público. Las afectaciones de la lucha contra el narcotráfico y entre los grupos criminales afectaron no solamente la dimensión social, sino que, también, las acciones de conservación de estas comunidades fueron limitadas, lo que ocasionó considerables pérdidas de capital social y otros recursos que son fundamentales para procurar la conservación ambiental y lograr el desarrollo. 
Lo más triste es que trabajamos por años con una comunidad y de repente ya no está, huyeron, los mataron o no sé... pero todo el tiempo, la inversión en los proyectos y todo se pierde, sin contar que son las comunidades las que apoyan en las labores de conservación, todo lo que hacemos se hace con apoyo de la gente. (Comunicación personal, 21.02.202O)

En esta situación se evidencia la pertinencia de visibilizar el impacto del narcotráfico en las ANP y las comunidades, ya que este fenómeno tiene implicaciones en todas las esferas del desarrollo sustentable (económicas, ambientales y sociales), con afectaciones a una de las figuras más importantes de la protección de la naturaleza: las áreas naturales protegidas.

\section{Amenazas actuales del narcotráfico para la conservación ambiental en las ANP}

A casi una década de haber terminado la guerra contra el narcotráfico, los enfrentamientos entre grupos criminales y de estos con las fuerzas del Estado, a lo largo del país, no han cesado. Los índices de inseguridad siguen siendo altos (Instituto Nacional de Estadística y Geografía, 2019), y las condiciones bajo las cuales se llevan a cabo acciones de conservación en las ANP siguen siendo inseguras. Los conflictos entre los grupos criminales dentro de las ANP son una realidad violenta en la que se encuentran las comunidades y el personal de conservación, y limitan su capacidad de desarrollar oportunamente los programas de monitoreo, investigación científica, ecoturismo, aprovechamiento y de desarrollo en las regiones. "Si te pudiera decir qué es lo que más nos afecta actualmente es la intensidad de los conflictos cuando un grupo A le disputa el territorio al grupo B y a la inversa" (comunicación personal, 21.02.2O2O). "El problema con esta ANP es que, en esta zona, coinciden dos grupos delictivos grandes, por lo que son constantes las peleas por los territorios" (comunicación personal, 02.04.2020).

La violencia generada por los conflictos entre los grupos criminales representa una de las principales amenazas a la conservación ambiental en las ANP de México, por lo que se han tenido que desarrollar, de manera empírica, estrategias para la prevención de situaciones de vulnerabilidad, como los cronogramas de violencia en las ANP y el diseño de protocolos de seguridad.

De hecho, ya sabemos nosotros cuándo es la temporada de conflicto, tenemos nuestro cronograma de violencia hecho por nosotros, los meses de mayor violencia es en el período agosto-octubre, porque es cuando cosechan la marihuana y la amapola y 
empiezan a movilizarla por el territorio para llevarla hasta la frontera con Arizona y Texas. (Comunicación personal, 08.05.2020)

Siempre nos reportamos con los vínculos entre el narcotráfico y las personas (...) para explicar la intención y el trabajo que vamos a hacer en las localidades (...), después de eso ya no hay problema, ya que las órdenes del "jefe llegan hasta las hormigas" [a todos los miembros del grupo criminal y personas de las comunidades]. Aunque sí hay un protocolo de seguridad para nuestro trabajo que nos dio la Gendarmería Ambiental, la verdad es que no nos sirve, hemos tenido que hacer cada uno los suyos, o sea, cada ANP de la región. (Comunicación personal, 19.02.2020)

En cuanto a la seguridad personal, los trabajadores de las ANP cuentan con un seguro de vida institucional que depende de las convocatorias laborales (p. e. Comisión Nacional de Áreas Naturales Protegidas, 2007); sin embargo, pueden solicitar seguros de vida particulares de acuerdo con sus necesidades. Al respecto, las personas entrevistadas mencionan que nunca han solicitado algún seguro de vida extra. Con relación a los servicios médicos, el personal de las ANP recibe atención médica en el Instituto de Seguridad y Servicios Sociales de los Trabajadores del Estado (ISSSTE), al igual que los demás servidores públicos en el país.

Tenemos un seguro de vida institucional, que no diferencia aquellos que se encuentran trabajando en campo de los que están en las oficinas; y, con relación a la atención médica, tenemos lo normal, ISSSTE, no tenemos algún seguro de gastos médicos mayores o algo así. (Comunicación personal, 08.05.2020)

Con relación a las medidas de seguridad, por disposición oficial, los trabajadores de la CONANP, o bien de la SEMARNAT, no pueden portar armas de fuego, únicamente los servidores públicos de las dependencias de seguridad pública como la Guardia Nacional, Fiscalías, Secretaría de la Defensa Nacional, Secretaría de Marina y policías federales y estatales -según el Art. 24 de la Ley Federal de Armas de Fuego y Explosivos-. Esta situación permite comprender las condiciones bajo las cuales se realizan las actividades de conservación en entornos de vulnerabilidad.

$\mathrm{Al}$ respecto, la Gendarmería Ambiental fue impulsada en el año 2016, con el objetivo de prevenir los delitos y faltas administrativas en materia de protección al medio ambiente, a través del intercambio de información entre la CONANP, la Procuraduría Federal de Protección al Ambiente y la Policía Federal (Secretaría de Seguridad y Protección Ciudadana, 2020). Sin embargo, como se muestra en el estudio, los protocolos de seguridad impulsados no han sido eficaces, por la heterogeneidad de contextos y características propias en cada grupo criminal. 
De igual manera, ha sido de utilidad para las estrategias de conservación en las ANP el apoyo de páginas de Facebook en donde se reportan situaciones de riesgo (SDR), como balaceras, ponchallantas (abrojos), retenes ilegales o persecuciones de gente armada en diversas zonas de las ciudades, comunidades, brechas o caminos rurales, etc. Estas páginas se han convertido en herramientas útiles para identificar conflictos armados casi en tiempo real, y se han desarrollado como estrategias confiables de prevención creadas por la misma población ante la vulnerabilidad social presente a lo largo del país.

Antes de salir a campo, verificamos en Facebook cómo está la situación, si vemos que esta peligroso posponemos el trabajo al siguiente día o la siguiente semana y tratamos de mantener comunicación constante con todos los miembros del equipo y las personas que nos apoyan. (Comunicación personal, 05.12.2019)

Estas estrategias identificadas permiten conocer y comprender el estado de indefensión y vulnerabilidad en el que se desarrollan las actividades de conservación en las ANP, mismas que se encuentran condicionadas por los problemas de seguridad pública, en los cuales las actuaciones del Estado han sido más que ineficaces para atender este fenómeno.

Como se ha mencionado a lo largo del estudio, una de las principales actividades que se realizan en las ANP son los monitoreos biológicos, método para conocer las dinámicas de los ecosistemas y los efectos de la intervención de los seres humanos. Por tanto, son esenciales, para garantizar la conservación, el manejo y aprovechamiento sustentable en distintos niveles de integración, desde los genes hasta las comunidades y ecosistemas (Chediack, 2009). Para obtener datos de los monitoreos se utilizan diversas tecnologías, como las cámaras trampa, las cuales son ubicadas de manera estratégica y permiten capturar imágenes accionadas por sensores de movimiento; sin embargo, en las ANP con presencia de grupos criminales generalmente son destrozadas o robadas, ya que las cámaras fotografían a sus integrantes dentro de las ANP (Figura 5). "Las cámaras trampa que usamos en el monitoreo de especies son constantemente robadas o destrozadas, pero, cuando no las ven, las cámaras los detectan y los fotografían" (comunicación personal, 19.03.2020).

En una comunidad en donde un compañero hacía monitoreo de felinos con cámaras trampa, miembros del grupo criminal le pidieron revisar las fotografías tomadas para asegurar que ninguna fotografía los hubiera captado (...); enfrente de ellos tuvo que borrar las fotos. (Comunicación personal, $02.04 .2 \mathrm{O} 2 \mathrm{O}$ ) 

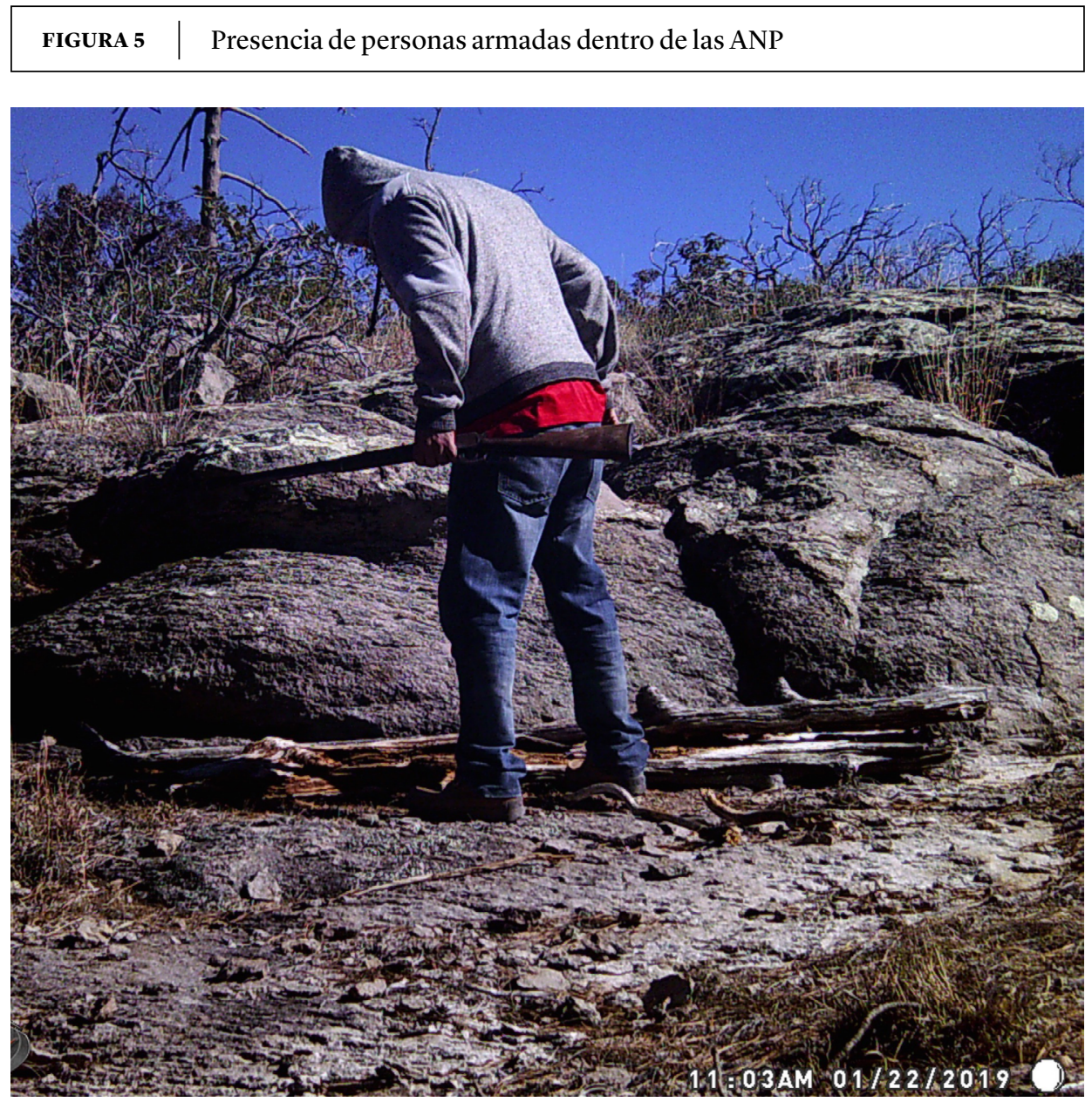

Fuente: imagen proporcionada por personal de las ANP.

Otra de las amenazas actuales de la presencia de estos grupos criminales en las ANP son los incendios forestales. Con relación a esto, el fenómeno de la deforestación por el narcotráfico ha sido documentado en otros países (Dávalos et al., 2011; McSweeney; Nielsen; Taylor; Wrathall; Pearson, 2014; Viña; Echavarría; Rundquist, 2004) donde la deforestación está relacionada con el cultivo de droga. Sin embargo, en México, el tema ha sido poco estudiado. Sainz (2018), en la investigación denominada Narcodeforestación en México, un vínculo ambivalente, menciona que los datos existentes sobre este fenómeno se derivan de reportes hemerográficos y de declaraciones oficiales por parte de representantes de las dependencias. En el estudio menciona que la deforestación en México, además de estar vinculada al 
narcotráfico, se realiza en áreas destinadas a la conservación (ANP) de estados como Puebla, Michoacán, Durango, Chihuahua, Veracruz, Morelos, Oaxaca y Chiapas.

Ahora están interesados en la madera, empezaron a extorsionar a los ejidatarios para extraer madera de manera ilegal (...). Todo lo que les deje dinero lo harán, sobre todo si existe una demanda del recurso. Ahora es común encontrar, incluso al lado de la carretera, nuevos aserraderos. (Comunicación personal, 19.03.2O2O)

En concordancia con lo reportado por Sainz (2018), los incendios forestales intencionales son una de las técnicas utilizadas para la deforestación por los grupos criminales, con el objetivo de hacer un cambio de uso de suelo para la siembra de droga. En ese sentido, en el presente estudio se identificó que los incendios provocados por estos grupos, además de tener fines de siembra ilegal de droga, se utilizan como estrategia de guerra en los casos de conflicto entre grupos, cuando coinciden en alguna zona, y se utiliza para sacar al otro grupo de sus lugares de asentamiento, pero en ocasiones los incendios se han salido de control, devastando extensas zonas de las ANP y llegando, incluso, a las comunidades cercanas.

Una de las cosas que más nos afectan de estos grupos en el ANP son los incendios forestales, ya sabemos que a finales de marzo y finales de junio es la temporada de incendios forestales naturales, o sea, los que ocasiona el calor o los rayos, pero hemos detectado que fuera de este período los incendios forestales son poco comunes, los provoca un grupo criminal para sacar de algún lugar a los miembros de otro grupo, de una barranca o de algún lugar, pero muchas veces el fuego no se detiene causando incendios por muchas hectáreas y que han llegado hasta la comunidades donde trabajamos. (Comunicación personal, 08.05.2020)

Con el recorte presupuestal para la CONANP en este sexenio, nos quedamos sin dinero para poder combatir los incendios (...), los jóvenes que nos auxilian con eso en el ANP trabajan con los que pueden, a veces tengo que conseguirles llantas usadas para el vehículo y hago lo imposible para comprarles sus uniformes (...), ni modo que combatan incendios en huaraches [sandalias]. (Comunicación personal, 19.03.2O2O)

Entre los desafíos actuales para la conservación, se encuentran los nuevos mercados con altas ganancias, como el cultivo de aguacate, lo que implica problemas serios de deforestación y pérdida de biodiversidad. En los últimos años se ha visto un creciente interés de los grupos criminales por este mercado en estados como Jalisco, Michoacán, Sinaloa y Oaxaca (El aguacate, 2019; La guerra de cárteles, 2017; Linthicum, 2019). 
La producción de aguacate está teniendo un impacto profundo en los mercados de los narcos, ahora ya no quieren únicamente dedicarse al negocio de la droga y la venta de madera, ahora quieren plantar aguacates en todos sus territorios, lo bueno de eso son los empleos, lo malo es que para sembrarlos tienen que deforestar (...), la preocupación, además, está en que metan las manos y ensucien el proceso. (Comunicación personal, 19.03.2020)

Esta situación coincide con lo establecido por Buscaglia, (2012); Carpio, Vargas, Villarreal, Santillana y Hernández, (2018b); Olinger (2013) y Williams (2010), acerca de la diversificación de las actividades de los grupos criminales a mercados redituables que les permitan continuar con su financiamiento y permanencia en los territorios de dominio.

\section{Narcotraficantes, los conservacionistas intermitentes}

Los discursos más positivos sobre la presencia de grupos criminales en las ANP han ocasionado que se les denomine conservacionistas intermitentes (Herp.mx, 2019). Al respecto, en este estudio se identificó que la presencia del narcotráfico en las ANP ha impactado de manera positiva para reducir otras actividades como la tala y la pesca ilegales, y la caza furtiva. Esto sucede porque la presencia de otras personas cerca de las zonas de acción de dichos grupos (rutas de tráfico, sembradíos de droga) representa un peligro para la industria del narcotráfico, por tanto, no permiten que personas ajenas al grupo se acerquen, lo que ha derivado en un impacto positivo para ciertas zonas. "La caza ilegal ha disminuido por la presencia de estos grupos en la zona" (comunicación personal, 08.05.2019).

La gente ya no entra a cazar animales, ni siquiera para consumo, anteriormente entraban a cazar venados, jabalíes y guajolotes, ahora ya no entran. Lo que sí hemos notado es que el bosque se mantiene más o menos intacto, nadie tala árboles, ni siquiera se acercan... sobre todo por miedo. (Comunicación personal, 02.04.2020)

La pesca ilegal en esta zona ha disminuido, las personas que venían en la noche o la madrugada a pescar de manera ilegal ya no vienen, porque a esas horas es cuando pasan los narcos con la droga y si los ven les va mal. (Comunicación personal, 28.11.2020)

$\mathrm{Al}$ respecto, el presente estudio coincide con lo reportado por Morales (2017), en Colombia, donde los grupos criminales propiciaron la conservación de grandes extensiones naturales quedando al margen de los grandes proyectos de desarrollo; sin embargo, hacen falta más estudios sobre el impacto ambiental de estos grupos 
en las ANP de México, para comprender este fenómeno desde todas las dimensiones de la sustentabilidad.

\section{Conclusiones}

El narcotráfico en México ha tenido profundos impactos sociales y económicos a lo largo del país, pero, como se evidenció en el presente estudio, también ha tenido repercusiones ambientales que, de manera directa e indirecta, han afectado diversas formas de conservación ambiental, en particular en las ANP. De igual manera, se concluye que, desde su origen, las ANP han estado vinculadas al narcotráfico por ser recursos estratégicos para el cultivo de droga, situación que ha sido determinante en el contexto de la conservación ambiental, en el diseño de nuevas estrategias para lograr la conservación y el desarrollo sustentable en las comunidades.

A su vez, se identifica que el impacto de estos grupos en las ANP no se ha limitado a las afectaciones ambientales, sino también al capital humano y social para la conservación, con violaciones a los derechos humanos y serias afectaciones al desarrollo de las comunidades. Se destacan, además, las capacidades de los servidores públicos de las ANP para enfrentar los desafíos en la implementación de estrategias para la conservación ambiental ante la presencia del narcotráfico en las ANP, a través del desarrollo de cronogramas de violencia y de la identificación de situaciones de riesgo (SDR), mediante plataformas de redes sociales como Facebook, como estrategias de prevención situacional con fines de conservación.

Por último, se concluye que existe la necesidad de fortalecer las voluntades políticas en materia de seguridad medioambiental en el país, de implementar protocolos de seguridad institucional para la conservación y fortalecer la cooperación de la población con las instituciones encargadas de la conservación en México a través de la educación ambiental.

\section{Referencias}

Alvarado, Israel (2012). Delincuencia organizada ambiental en México, una nueva manifestación criminal del tráfico de especies. Revista Criminalidad, 54(1), 283-311. Recuperado de http:// www.scielo.org.co/pdf/crim/v54n1/v54n1a05.pdf

Aridjis, Homero (31 de enero de 2020). En México te matan por defender la naturaleza. New York Times. Recuperado de https://www.nytimes.com/es/2020/01/31/espanol/opinion/ homero-gomez-mexico.html 
Arroyo-Quiroz, Inés; Wyatt, Tanya (2018). Green Crime in México: A Collection of Case Studies. Reino Unido: Palgrave Mcmillan.

Astorga, Luis (2005). El siglo de las drogas: el narcotráfico, del porfiriato al nuevo milenio. México: Plaza y Janés.

Ávila, Fátima (2015). Diferencias entre las organizaciones criminales y su efecto en el uso de la violencia (Tesina). Centro de Investigación y Docencia Económicas, Licenciatura en Ciencia Política y Relaciones Internacionales, México. Recuperado de http://repositorio-digital. cide.edu/bitstream/handle/11651/496/145429.pdf? sequence=1

Barrios, María (2020). Migración por violencia. Dicotomía del desplazamiento interno forzado en Ciudad Juárez. Nexos Observatorio Migrante-Blog de movilidad poblacional. Recuperado de https://migracion.nexos.com.mx/2020/03/migracion-por-violencia-dicotomia-deldesplazamiento-interno-forzado-en-ciudad-juarez/

Bernard, Russell (2006). Nomprobability Sampling and Choosing Informants. En Research methods in anthropology. Qualitative and quantitative approaches (pp. 186-209). Editado por Bernard Russell. California: Oxford. AltaMira Press. Recuperado de http://www. cycledoctoralfactec.com/uploads/7/9/0/7/7907144/\%5Bh._russell_bernard\%5D_ research_methods_in_anthropol_bokos-z1_1_.pdf

Buscaglia, Edgardo (2012). La Paradoja Mexicana de la Delincuencia Organizada: Policía, violencia y corrupción. Revista Policía y Seguridad Pública, 1(2), 271-282. https://doi. org/10.5377/rpsp.v1i2.1365

Carpio, Jose; Vargas, Cynthia; Villarreal, Karla; Meraz, Maite (2018). Las redes sociales como factor criminógeno de la venta ilegal de especies en Tamaulipas (México): el caso de Facebook. CienciaUAT, 13(1), 19-34. Recuperado de http://www.revistaciencia.uat.edu. $\mathrm{mx} /$ index.php/CienciaUAT/article/view/972/466

Carpio, José; Vargas, Cynthia; Villarreal, Karla; Santillana, Rafael; Hernández, Ignacio (2018). Percepción criminológica de la posesión de animales del narcotráfico en Tamaulipas, el zoológico del crimen organizado. Letras Jurídicas, 26, 1-20.

Castañeda, Javier (2006). Las Áreas Naturales Protegidas de México de su origen precoz a su consolidación tardía. Script Nova Revista Electrónica de Geografía y Ciencias Sociales, 10(128). Recuperado de http://www.ub.edu/geocrit/sn/sn-218-13.htm

Centro de Estudios Sociales y de Opinión Pública (2006). Seguridad Pública. Recuperado de http://archivos.diputados.gob.mx/Centros_Estudio/Cesop/Comisiones/dtseguridad\%20 publica1.htm\#[Citar\%20como

Centro Mexicano de Derecho Ambiental (2019). Informe sobre la situación de las personas defensoras de los derechos humanos ambientales. Recuperado de https://www.cemda.org. $\mathrm{mx} /$ wp-content/uploads/2020/03/informe-personas-defensoras-2019.pdf 
Cepeda, Fernando (2011). Narcotráfico, financiación política y corrupción. Bogotá: Ecoe.

Chabat, Jorge (2015). Violence in Mexico. In Search of an Explanation. En Reconceptualizing security in the Americas in the twenty-first century (pp.103-113), compilado por Bruce Bagley; Jonathan D. Rosen; Hanna S. Kassab. Lanham, MD: Lexington Books.

Chediack, Sandra (2009). Monitoreo de biodiversidad y recursos naturales ¿para qué? México: CONABIO. Recuperado de http://www.oikos.unam.mx/LECT/images/Libros/ mmrjrgj_2009.pdf

Comisión Nacional de Áreas Naturales Protegidas (2007). Convocatoria CONANP 008-07. Diario Oficial de la Federación. Recuperado de http://www.dof.gob.mx/ vacantes/3840/001967.htm

Comisión Nacional de Áreas Naturales Protegidas (2019). Áreas Naturales decretadas. Gobierno de México. Recuperado de http://sig.conanp.gob.mx/website/pagsig/datos_anp.htm

Comisión Nacional de Áreas Naturales Protegidas (2020). Áreas Naturales Protegidas. Gobierno de México. Recuperado de https://www.gob.mx/conanp

Comisión Nacional de Derechos Humanos (2019). Estudios sobre el cumplimiento e impacto de las recomendaciones generales, informes especiales y pronunciamientos de la CNDH 2001-2017 Investigación para la Comisión Nacional de los Derechos Humanos (Tomo VI). México: CNDH-UNAM. Recuperado de https://www.cndh.org.mx/sites/default/files/ documentos/2019-03/ANP-DH.pdf

Comisión Nacional para el Conocimiento y Uso de la Biodiversidad (2006). Capital natural y bienestar social. Gobierno de México. Recuperado de https://www.biodiversidad.gob.mx/ media/1/pais/files/capital_natural_2EP.pdf

Comisión Nacional para el Conocimiento y Uso de la Biodiversidad (2009). Síntesis del Capital Natural. Gobierno de México. Recuperado de https://www.biodiversidad.gob.mx/media/1/ pais/files/capital_natural_2EP.pdf

Comisión Nacional para el Conocimiento y Uso de la Biodiversidad (2020). ¿Por qué se pierde la biodiversidad? Biodiversidad mexicana. Recuperado de https://www.biodiversidad.gob. $\mathrm{mx} /$ biodiversidad/porque

Crespo, Ricardo (2008). La naturaleza como sujeto de derechos: ¿símbolo o realidad jurídica? Recuperado de https://therightsofnature.org/wp-content/uploads/pdfs/Espanol/Crespo_ natureleza_sujeto_2008.pdf

Cruz, Estefanía (2017). Movilidad forzada por las dinámicas del narcotráfico: variables para el análisis del proceso de asilo de mexicanos por violencia en EE. UU. Foro Internacional, 57(3), 576-606. http://dx.doi.org/10.24201/fi.v52i3.2449 
Dávalos, Liliana; Bejarano, Adriana; Hall, Mark; Correa, Leonardo; Corthals, Angelique; Espejo, Oscar (2011). Forest and Drugs: Coca-driven Deforestation in Tropical Biodiversity Hotspots. EnvironmentalScience and Technology, 45(4),1219-1227.http://dx.doi.org/10.1021/ es102373d

Durin, Séverine (2012). Los que la guerra desplazó: familias del noreste de México en el exilio. Desacatos, 38, 29-42. Recuperado de http://www.scielo.org.mx/scielo.php?script=sci_ arttext\&pid=S1607-050X2012000100003

El aguacate, otra víctima más del narcotráfico (27 de junio de 2019). CC News. Recuperado de: https://news.culturacolectiva.com/mexico/productores-aguacate-son-victimas-deextorsiones-del-narco-en-mexico/

El narcotráfico y la tala ilegal aprovechan la protección de áreas de Mesoamérica (22 de noviembre de 2018). EFE verde. Recuperado de https://www.efeverde.com/noticias/ narcotrafico-tala-ilegal-areas-protegidas-mesoamerica/

Este es el mapa del narcotráfico en México a 10 meses de la llegada de López Obrador al poder (18 de octubre de 2019). Infobae México. Recuperado de https://www.infobae.com/ america/mexico/2019/10/19/este-es-el-mapa-del-narcotrafico-en-mexico-a-10-mesesde-la-llegada-de-lopez-obrador-al-poder/

Fuerte, María (2016). Geografía de la violencia en México. Un acercamiento a la reconfiguración territorial de la violencia generada por el crimen organizado. México: Centro de Investigación y Docencia Económicas. Recuperado de http://www.politicadedrogas.org/PPD/ documentos/20161106_164436_15_geografi\%CC\%81aviolenciafinal_281016.pdf

García, Sergio (2002). En torno a la seguridad pública. Desarrollo penal y evolución del delito. En Los desafios de la seguridad pública en México (pp. 81-98), compilado por José Peñaloza; Mario Garza. México: Universidad Iberoamericana. Recuperado de https:// archivos.juridicas.unam.mx/www/bjv/libros/1/419/10.pdf

Gaussens, Pierre (2018). La otra montaña roja: el cultivo de la amapola en Guerrero. Textual: análisis del medio rural latinoamericano, 71, 33-69. https://doi.org/10.5154/r. textual.2017.71.003

González, Héctor; Cortés, Patricia; Iñiguez, Luis; Ortega, Alfredo (2014). Las Áreas Naturales Protegidas en México. Investigación y Ciencia, 22(60), 7-15. Recuperado de https://www. redalyc.org/pdf/674/67431160002.pdf

Hernández, Anabel (2014). Los señores del narco. México: Grijalbo. Recuperado de https:// zoonpolitikonmx.files.wordpress.com/2014/02/los-sec3b1ores-del-narco.pdf

Hernández, Luis (6 de octubre de 2009). El narcotráfico y la sociedad rural. La Jornada. Recuperado de https://www.jornada.com.mx/2009/10/06/opinion/014a1pol 
Herp.mx (20 de mayo de 2019). Narcos, los conservacionistas intermitentes. Recuperado de https://es-la.facebook.com/herpmx/posts/narcos-the-fickle-conservationistsdrugcultivation-is-a-double-edged-sword-for-m/2305989742794969/

Impacta narcotráfico Áreas Naturales Protegidas de México (6 de enero de 2013). Verde Bandera Periodismo Ambiental. Recuperado de https://verdebandera.mx/impacta-el-narcotraficoareas-naturales-protegidas-de-mexico/

Instituto Nacional de Estadística y Geografía (2019). Incidencia delictiva en México. Recuperado de https://www.inegi.org.mx/temas/incidencia/

Ismael, Eduardo (7 de mayo de 2019). Áreas naturales protegidas en México están en control de grupos criminales. Breaking. Recuperado de https://breaking.com.mx/2019/05/areasnaturales-protegidas-en-mexico-estan-en-control-de-grupos-criminales/

La guerra de cárteles detrás del negocio del aguacate; Michoacán, Jalisco y Sinaloa principales "minas" (30 de mayo de 2017). Sin Embargo. Recuperado de https://www.sinembargo. $\mathrm{mx} / 30-05-2017 / 3228763$

Linthicum, Kate (21 de noviembre de 2019). La guerra del narco para controlar la multimillonaria industria del aguacate en México. Los Ángeles Times. Recuperado de https://www.latimes. com/espanol/mexico/articulo/2019-11-21/mexico-cartel-violencia-aguacates

Malamud, Carlos; García, Carlota (2011). El conflicto fronterizo entre Costa Rica y Nicaragua: ¿medio ambiente, soberanía, narcotráfico o mero instrumento electoral? Real Instituto Elcano. Recuperado de http://biblioteca.ribei.org/2045/1/ARI-22-2011.pdf

Maldonado, Salvador (2011). Drogas, violencia y militarización en el México rural. El caso de Michoacán. Revista Mexicana de Sociología, 24(1), 5-39. Recuperado de http://www.scielo. org.mx/pdf/rms/v74n1/v74n1a1.pdf

Martínez, Marco (3 de marzo de 2015). Afecta crimen organizado monitoreo de ANP en entidades: CONANP. Quadrantin México. Recuperado de https://mexico.quadratin.com. $\mathrm{mx} /$ Afecta-crimen-organizado-monitoreo-de-ANP-en-entidades-Conanp/

McSweeney, Kendra; Nielsen, Erik; Taylor, Matthew; Wrathall, David; Pearson, Zoe (2014). Drug Policy as Conservation Policy: Narco-Deforestation. Science, 343, 489-490. http:// dx.doi.org/10.1126/science.1244082

Melgoza, Alejandro (5 de mayo de 2019). Las Áreas Naturales Protegidas, paraíso de bandas criminales. Proceso. Recuperado de https://www.proceso.com.mx/582409/las-areasnaturales-protegidas-paraiso-de-bandas-criminales

Méndez, Ernesto (23 de febrero de 2015). Delincuencia frena creación de áreas naturales protegidas. Excélsior. Recuperado de https://www.excelsior.com.mx/ nacional/2015/02/23/1009871 
Moloesnik, Marcos; Suárez de Garay, María (2012). El proceso de militarización de la seguridad pública en México (2006-2012). Frontera Norte, 24(48), 121-144. Recuperado de http:// www.scielo.org.mx/pdf/fn/v24n48/v24n48a5.pdf

Morales, Lorenzo (2017). La paz y la protección ambiental en Colombia: propuestas para un desarrollo rural sostenible. Recuperado de http://static.iris.net.co/sostenibilidad/upload/ documents/envt-colombia-esp_web-res_final-for-email.pdf

Muedano, Marcos (26 de noviembre de 2018). Dominan 80 células del narco en México, operan 6 cárteles. Excélsior. Recuperado de https://www.excelsior.com.mx/nacional/dominan80-celulas-del-narco-en-mexico-operan-seis-carteles/1280724

Nájar, Alberto (14 de diciembre de 2010). El "apoyo social” del narcotráfico mexicano. BBC News. Recuperado de https://www.bbc.com/mundo/noticias/2010/12/101213_ narcotrafico_mexico_base_social_lav

Nájar, Alberto (11 de julio de 2017). Los mapas que muestran los radicales cambios de influencia territorial de los cárteles del narcotráfico en México. BBC News. Recuperado de https:// www.bbc.com/mundo/noticias-america-latina- 40576103

Núñez, Adolfo (1999). El narcotráfico en el Perú: estrategias conjuntas de las Fuerzas Armadas y la policía nacional para su erradicación. Boletín de Información, 260, 79-85. Recuperado de https://dialnet.unirioja.es/servlet/articulo?codigo $=4626338$

Olinger, Mariana (2013). La propagación del crimen organizado en Brasil: una mirada a partir de los ocurrido en la última década. En La diáspora criminal: la difusión trasnacional del crimen organizado y cómo contener su expansión (pp.101-142), compilado por Juan Garzón; Eric Olson. Washington, DC: Wilson Center. Recuperado de https://www.wilsoncenter. org/sites/default/files/media/documents/publication/LA_DIASPORA_CRIMINAL.pdf

Organización de las Naciones Unidas (1992). Convenio de Diversidad Biológica. Recuperado de https://www.cbd.int/doc/legal/cbd-es.pdf

Ortiz, Román (2019). Cárteles y bandas en la cuenca del Caribe: ¿crimen común o amenaza antiestatal? Madrid: IEEE. Recuperado de http://www.ieee.es/Galerias/fichero/docs_ investig/2019/DIEEEINV01-2019Carteles.pdf

Palacios, Marco; Serrano, Mónica (2010). Colombia y México: las violencias del narcotráfico. En Los grandes problemas de México (XV). Seguridad nacionaly seguridad interior (pp. 105154), compilado por Arturo Alvarado; Mónica Serrano. México: El Colegio de México. Recuperado de https://2010.colmex.mx/16tomos/XV.pdf

Paz, María; Risdell, Nicholas (2014). Conflictos, conflictividadesy movilizaciones socioambientales en México: problemas comunes, lecturas diversas. México: Porrúa. Recuperado de https:// www.crim.unam.mx/web/sites/default/files/Conflictos\%20y\%20conflictividades_0.pdf 
Peralta, Laila (2018). Los tribunales verdes en México. La sustentabilidad en la Ley Ambientaly la construcción de un nuevo paradigma institucional. México: Colofón.

Pereyra, Guillermo (2012). México: violencia criminal y "guerra contra el narcotráfico". Revista Mexicana de Sociología, 74(3), 429-460. Recuperado de http://www.scielo.org.mx/pdf/ rms/v74n3/v74n3a3.pdf

Rivera, Jaime (2014). Crimen organizado y autodefensas en México: el caso de Michoacán. Bogotá: Friedrich Ebert Stiftung. Recuperado de http://library.fes.de/pdf-files/bueros/ la-seguridad/10845.pdf

Rojas-Soriano, Raúl (2015). Aspectos teóricos sobre el proceso de formación de investigadores sociales. En Investigación Educativa, abriendo las puertas al conocimiento (pp. 25-31), compilado por Laura Abero, Lilián Berardi, Alejandra Capocasale, Selva García y Raúl Rojas. Uruguay: Consejo Latinoamericano de Ciencias Sociales (CLACSO). Recuperado de https://raulrojassoriano.com/cuallitlanezi/wp-content/themes/raulrojassoriano/assets/ libros/investigacion-educativa-raul-rojas-soriano.pdf

Rosen, Jonathan; Zepeda, Roberto (2015). La guerra contra el narcotráfico en México: una guerra perdida. Reflexiones, 94(1), 153-168. Recuperado de https://www.scielo.sa.cr/pdf/ reflexiones/v94n1/1659-2859-reflexiones-94-01-00153.pdf

Rubio, Laura (2014). Desplazamiento interno inducido por la violencia: una experiencia global, una realidad mexicana. México: ITAM. Recuperado de http://www.cmdpdh.org/publicacionespdf/libro_desplazamiento_una_realidad_mexicana.pdf

Sainz, Jaime (2018). Narcodeforestación en México. Un vínculo ambivalente. En Las Violencias, en busca de la política pública detrás de la guerra contra las drogas (pp. 51-74), compilado por Laura Atuesta; Alejandro Madrazo. México: Coyuntura y Ensayo/ CIDE.

Secretaría de Medio Ambiente (2020). Áreas Naturales Protegidas. Gobierno de la Ciudad de México. Recuperado de https://sedema.cdmx.gob.mx/programas/programa/areasnaturales-protegidas

Secretaria de Medio Ambiente y Recursos Naturales (2015). Informe de la situación del medio ambiente en México 2015. Compendio de estadísticas ambientales, indicadores clave, de desempeño ambiental y crecimiento verde. Recuperado de https://apps1.semarnat.gob. mx:8443/dgeia/informe15/tema/pdf/Informe15_completo.pdf

Secretaría de Seguridad y Protección Ciudadana (2020). División de Gendarmería Ambiental. Gobierno de México. Recuperado de https://www.gob.mx/sspc/acciones-y-programas/ gendarmeria-ambiental-162737

Simonian, Lane (1999). La defensa de la tierra del jaguar. Una historia de conservación en México. México:CONABIO/SEMARNAP. Recuperado de http://centro.paot.org.mx/documentos/ semarnat/defensa_jaguar.pdf 
Soberanes, Rodrigo (13 de abril de 2020). COVID-19 no detiene el asesinato de defensores ambientales en México. Mongabay Latam. Recuperado de https://es.mongabay. com/2020/04/mexico-covid-19-violencia-defensores-ambientales/

Solera, Claudia (20 de octubre de 2019). En Culiacán, los jóvenes hallan apoyo con los narcos. Excélsior. Recuperado de https://www.excelsior.com.mx/nacional/en-culiacanlos-jovenes-solo-hallan-apoyo-con-los-narcos/1342941

Sosa, J. (2011). Aplicación de la Ley para el Combate del Tráfico Ilegal de Vida Silvestre en México: el caso de Charco Cercado. Revista Therya, 2(3), 245-262. Recuperado de http:// www.scielo.org.mx/pdf/therya/v2n3/v2n3a5.pdf

Sumano, Andrés (2020). Impacto de la crisis del COVID-19 en la seguridad pública. En COVID-19 y frontera noreste, primeros impactos en migración, políticas públicas y población (pp. 34-39). México: Colegio de la Frontera Norte. Recuperado de https://www.clacso.org/ wp-content/uploads/2020/05/COVID_Matamoros-1.pdf

Toledo, Víctor (2015). El ecocidio en México. La batalla final es por la vida. México: Grijalbo.

Valdés, Guillermo (2013). Historia del narcotráfico en México. México: Aguilar.

Vargas, Fernando (1997). Parques Nacionales de México. Aspectos físicos, sociales, legales, administrativos, recreativos, biológicos, culturales, situación actual y propuestas en torno a los parques nacionales de México. México: Instituto Nacional de Ecología/SEMARNAP. Recuperado de http://www.paot.mx/centro/ine-semarnat/anp/AN07.pdf

Vázquez, Miguel (2018). Conservación de la naturaleza y áreas naturales protegidas en territorios de pueblos originarios de la frontera sur de México. Sociedad y Ambiente, 5(15), 117-130. Recuperado de http://www.scielo.org.mx/pdf/sya/n15/2007-6576-sya-15-117.pdf

Velázquez, Ana (2017). Desplazamiento interno por violencia en México. Causas, consecuencias y responsabilidades. México: CNDH. Recuperado de http://www.corteidh.or.cr/tablas/ r37820.pdf

Villatoro, Carolina (2012). Aspectos socioculturales e imágenes del narcotráfico. Imagonautas, 3(1), 56-75. Recuperado de http://imagonautas.webs.uvigo.gal/index.php/imagonautas/ issue/view/18

Viña, Andrés; Echavarría, Fernando; Rundquist, Donald (2004). Satellite Change Detection Analysis of Deforestation Rates and Patterns Along the Colombia-Ecuador Border. Ambio, 33(3), 118-125. https://doi.org/10.1579/0044-7447-33.3.118

Williams, Phil (2010). El crimen organizado y la violencia en México: una perspectiva comparativa. Istor Revista de Historia Internacional.11(42), 15-40. Recuperado de http:// www.istor.cide.edu/archivos/num_42/dossier2.pdf 